\title{
Successful Treatment of Refractory Vitiligo with a Combination of Khellin and 308-nm Excimer Lamp: An Open-Label, 1-Year Prospective Study
}

\author{
Samy Fenniche $\cdot$ Anissa Zaouak - Azima Ben Tanfous · Meriem Jrad • \\ Houda Hammami
}

Received: November 13, 2017 / Published online: December 27, 2017

(C) The Author(s) 2017. This article is an open access publication

\section{ABSTRACT}

Introduction: Phototherapy is the cornerstone of treatment of vitiligo. The 308-nm excimer lamp (EL) induces $\mathrm{T}$ cell apoptosis and the stimulation of melanocyte proliferation. Khellin is a furanochromone with a chemical structure close to psoralens. The objective of the study was to evaluate the safety and efficacy of 1-year treatment of recalcitrant vitiligo with a combination of 308-nm EL and khellin.

Methods: Twenty patients with resistant vitiligo were included. Khellin was applied $45 \mathrm{~min}$ before irradiation with EL, twice a week, at a dose of $250 \mathrm{~mJ} / \mathrm{cm}^{2}$. The repigmentation was assessed in four categories: excellent repigmentation (ER) (>75\% repigmentation), good repigmentation (GR) (50-75\% repigmentation), moderate repigmentation (MR) (25-50\%

Enhanced content To view enhanced content for this article go to www.medengine.com/Redeem/ FEFCF0604F9C5B6C.

S. Fenniche $(\varangle) \cdot$ A. Zaouak · A. B. Tanfous .

M. Jrad · H. Hammami

Dermatology Department, Habib Thameur Hospital, Tunis, Tunisia

e-mail: samy.fenniche@gmail.com

S. Fenniche - A. Zaouak - A. B. Tanfous - M. Jrad

H. Hammami

Laboratory of Genodermatosis and Cancer

(LR12SP03), Faculty of Medecine Tunis, University

of Tunis El Manar, Tunis, Tunisia repigmentation), and poor repigmentation (PR) $(<25 \%$ repigmentation).

Results: An ER was observed in $45 \%$ of patients $(9 / 20), 5 / 20(25 \%)$ achieved a GR, 3/20 (15\%) an MR, and 3/20 (15\%) a PR. Better response was observed on the face, neck, upper limb, hands, and abdomen. The mean number of procedures was 54.1 and the mean cumulative dose was $2967.5 \mathrm{~mJ} / \mathrm{cm}^{2}$. Six months after the last session no recurrences were observed.

Conclusion: The combination of 308-nm EL and khellin is a safe and effective treatment and represents a new alternative therapy for vitiligo. Further comparative controlled randomized investigations are needed to confirm these promising results with the appropriate therapeutic protocols.

Keywords: Excimer; Khellin; UVB; Vitiligo

\section{INTRODUCTION}

Vitiligo is an acquired skin disorder affecting $0.5-2 \%$ of the population worldwide, characterized by solitary or multiple well-defined depigmented macules [1]. The treatment of vitiligo is always a challenge for dermatologists because there is no definitive curative treatment. Several treatment options are available for vitiligo such as topical or systemic corticosteroids, calcineurin inhibitors, vitamin D analogues, systemic therapies, and surgery [2]. Phototherapy is the cornerstone of treatment of vitiligo. It 
modulates the immune response and induces an activation of hair follicle and epidermal melanocyte precursors by ultraviolet (UV) light. Conventional phototherapy is available as broadband UVB (290-320 nm) or more commonly narrowband UVB (311-313 nm). Targeted phototherapy is particularly indicated in patients with localized vitiligo. The monochromatic excimer light $(308 \mathrm{~nm})$ delivers higher fluence to the depigmented lesions while sparing the normal skin [3, 4]. In fact, hair follicle is the main reservoir that supplies melanocytes in repigmenting human vitiligo. UV exposure will stimulate proliferation and migration of melanocyte precursors along the infundibulum outer root sheath to the interfollicular epidermis [5]. Khellin is a furanochromone extracted from the seeds of Ammi visnaga (khella), a plant common in the Eastern Mediterranean region, and has a chemical structure close to psoralens with similar phototherapeutic properties but with less phototoxic and carcinogenic effects. It has previously proven its efficacy in vitiligo in association with UVA [6]. The combination therapy has become the first-line treatment of vitiligo and many reports have proved the efficacy of 308-nm excimer light in association with other kinds of drugs [7-10]. So, we evaluate in this study the safety and efficacy of 308-nm excimer lamp (EL) and topical khellin in the treatment of recalcitrant localized vitiligo.

\section{METHODS}

\section{Patients}

We conducted an open-label, prospective study in the dermatology department of Habib Thameur Hospital in Tunis from November 2015 to November 2016 including 20 patients with resistant localized vitiligo. Informed consent was obtained from all subjects after the ethical committee approval (medical ethics committee at the Habib Thameur Teaching Hospital, Tunis). Patients were free of treatment for at least 3 months. Any patient with history of photosensitive disorders, psychological disorders, skin cancer, autoimmune diseases, or any pregnant patient was excluded. All patients failed or reported poor results with previous treatment including topical corticosteroids, calcineurin inhibitors, antioxidant oral therapy, or narrow band UVB phototherapy.

\section{Study Design and Treatment Regimens}

Treatment protocol consisted in application of topical khellin, encapsulated in nanosomes (Vitises KT lotion, Sesderma, Spain) on vitiligo patches $45 \mathrm{~min}$ before UV irradiation. The peripheral area of targeted patches was protected from irradiation with a topical sunscreen applied $1 \mathrm{~h}$ prior to treatment. The UVB light was delivered with a 308-nm EL (Excilite $\mu$, Deka Medical Lasers, Florence, Italy), twice a week, at a dose of $250 \mathrm{~mJ} / \mathrm{cm}^{2}$. If no side effects occurred, the dose was increased by $50 \mathrm{~mJ}$ every next session. If erythema persisted for more than $48 \mathrm{~h}$ the dose was reduced to the last well-tolerated one. If burning or blistering developed the treatment was skipped until complete healing. Therapy was applied as long as the repigmentation process continued and was interrupted if there was no evidence of new repigmentation in vitiligo-affected skin areas after 16 sessions. The patients were also advised to apply sun block after the session. Collected patient data included age, sex, disease duration, lesions areas, side effects, session numbers, and maximal and total dose delivered.

\section{Assessment of Treatment Efficacy}

Assessment of efficacy was based on the percentage of repigmentation of the treated area by two independent dermatologists comparing photographs before and after treatment. The repigmentation was assessed in four categories: excellent repigmentation (ER) (>75\% repigmentation), good repigmentation (GR) (50-75\% repigmentation), moderate repigmentation (MR) (25-50\% repigmentation), and poor repigmentation $(\mathrm{PR})(<25 \%$ repigmentation).

\section{Statistical Analysis}

Statistical analysis was performed using Statistical Package for the Social Sciences (IBM SPSS 
20). Correlations between the duration of the disease, vitiligo treated area, the number of procedures, and the clinical outcome were determined by the Chi-squared test and Fisher's exact test. Statistical significance was defined by a $P$ value of less than 0.05 . All patients were followed up 6 months after the last session.

\section{RESULTS}

A total of 20 patients with localized vitiligo were included. There were 16 women and 4 men (range 4-44 years, median 29.15 years). Mean evolution of the disease was 26.5 months (range 10-60 months). Clinical data of patients are summarized in Table 1. Localizations of vitiligo areas were cheek [2], forehead, chin, neck [4], periorbital area, retroauricular region, elbows, breast, wrist, knee, forearm [2], hands, abdomen [2], and upper limb. The distribution of lesions and their response to therapy are shown in Table 2. The mean number of procedures was 54.1 (range 24-96), the maximal dose was $4500 \mathrm{~mJ} / \mathrm{cm}^{2}$, and the mean cumulative dose delivered was $2967.5 \mathrm{~mJ} / \mathrm{cm}^{2}$ (range $1300-4500 \mathrm{~mJ} / \mathrm{cm}^{2}$ ).

Table 1 Patients demographics and disease characteristics

\begin{tabular}{|c|c|}
\hline Mean age (range), years & $29.15(4-44)$ \\
\hline Male/female & $16 / 4$ \\
\hline $\begin{array}{l}\text { Fitzpatrick skin } \\
\text { phototype }\end{array}$ & $\begin{array}{l}\text { III (3 patients), IV (14 patients), } \\
\text { V (3 patients) }\end{array}$ \\
\hline $\begin{array}{l}\text { Duration } \\
\qquad \text { (months) } \pm \mathrm{SD}\end{array}$ & $26.5 \pm 13.5$ \\
\hline Sites of lesions & $\begin{array}{l}\text { Cheek [2], forehead, chin, neck } \\
\text { [4], eyes, retroauricular, } \\
\text { elbows, breast, wrist, knee, arm, } \\
\text { forearm [2], hands, abdomen } \\
\text { [2] }\end{array}$ \\
\hline $\begin{array}{l}\text { Mean number of } \\
\text { sessions, } \pm \mathrm{SD}\end{array}$ & $54.1 \pm 37.7$ \\
\hline $\begin{array}{l}\text { Mean cumulative dose } \\
\qquad\left(\mathrm{mJ} / \mathrm{cm}^{2}\right) \pm \mathrm{SD}\end{array}$ & $2967.5 \pm 1147.4$ \\
\hline
\end{tabular}

Table 2 Distribution of lesions and response to therapy

\begin{tabular}{|c|c|c|c|}
\hline Sites & $\begin{array}{l}\text { Number } \\
\text { of } \\
\text { sessions }\end{array}$ & Results & $\begin{array}{l}\text { Cumulative dose } \\
\text { delivered }(\mathrm{mJ} / \\
\left.\mathrm{cm}^{2}\right)\end{array}$ \\
\hline $\begin{array}{l}\text { Cheek (2 } \\
\text { patients) }\end{array}$ & 48,56 & GR, ER & 2650,2850 \\
\hline Forehead & 40 & ER & 2600 \\
\hline Chin & 40 & ER & 2500 \\
\hline $\begin{array}{l}\text { Neck }(4 \\
\text { patients) }\end{array}$ & $\begin{array}{l}32,48,40 \\
\quad 40\end{array}$ & $\begin{array}{c}\text { MR, ER, } \\
\text { GR, } \\
\text { GR }\end{array}$ & $2375^{*}$ \\
\hline Eyes & 24 & MR & 1300 \\
\hline $\begin{array}{l}\text { Retro } \\
\text { auricular }\end{array}$ & 24 & PR & 1500 \\
\hline Elbows & 96 & ER & 4500 \\
\hline $\begin{array}{c}\text { Forearm (2 } \\
\text { patients) }\end{array}$ & 82,96 & GR, ER & 4500 \\
\hline Wrist & 24 & PR & 1600 \\
\hline Hands & 96 & GR & 4500 \\
\hline Breast & 48 & MR & 2900 \\
\hline $\begin{array}{l}\text { Abdomen } \\
\qquad(2 \\
\text { patients })\end{array}$ & 56,72 & ER & 3600,4400 \\
\hline Knee & 24 & PR & 1600 \\
\hline Arm & 96 & ER & 4500 \\
\hline
\end{tabular}

$E R$ excellent repigmentation, $G R$ good repigmentation, $M R$ moderate repigmentation, $P R$ poor repigmentation ${ }^{*}$ Average

Both follicular and peripheral repigmentation were progressively observed during treatment. The shortest period showing signs of pigmentation was 1 month (8 sessions) and the longest period was 2 months (16 sessions). At the end of the 1-year study, 9/20 (45\%) patients achieved an ER, 5/20 (25\%) achieved a GR, 3/20 $(15 \%)$ an MR, and 3/20 (15\%) obtained a PR. Better responses were observed on the arm (Fig. 1), face, neck, elbows (Fig. 2), forearm (Fig. 3), hands (Fig. 4), and abdomen. The 

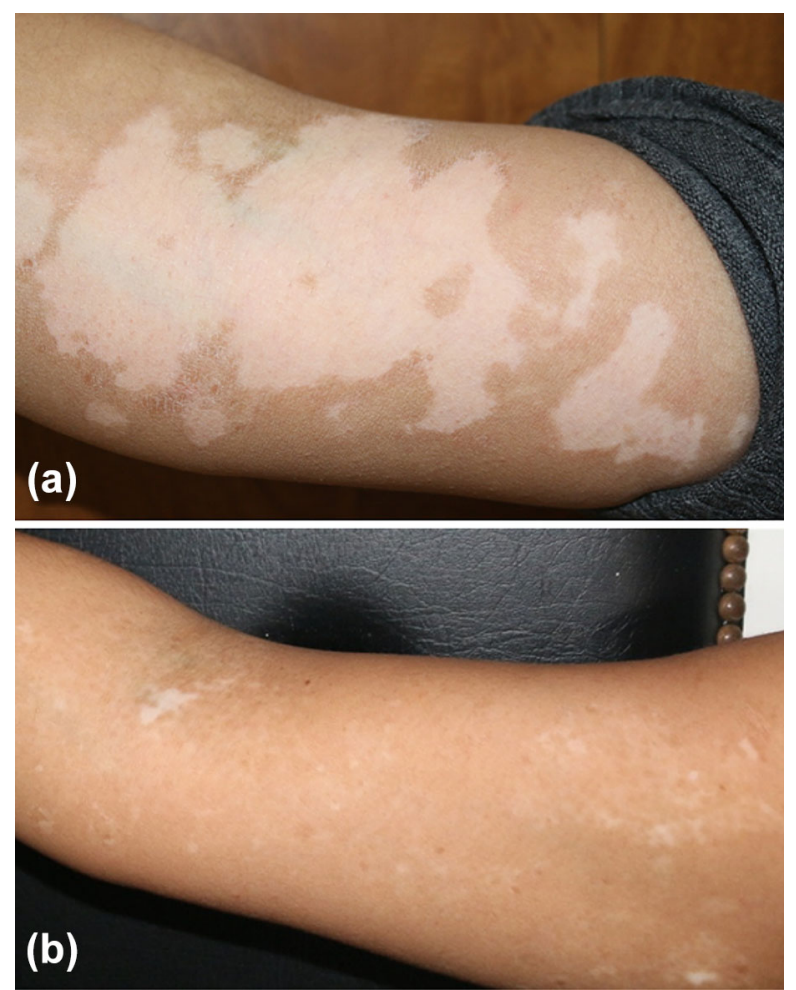

Fig. 1 a Vitiligo of the arm before treatment. b Almost $100 \%$ repigmentation 1 year after treatment

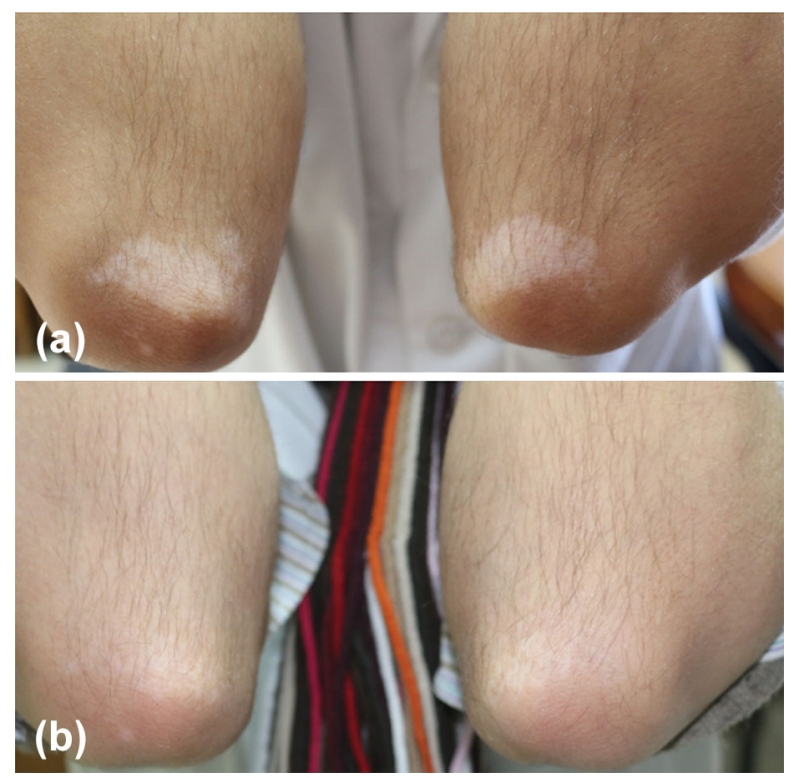

Fig. 2 a Vitiligo of the elbows before treatment. b > 75\% repigmentation 1 year after treatment resistant areas were retroauricular region, periorbital area, breast, wrist, and knee.

The repigmentation of lesions was significantly higher when disease duration was less than 2 years $(P=0.02)$ and the number of sessions more than $24(P=0.03)$. However, no statistically significant differences were seen between repigmentation score and vitiligo sites, sex or age $(P=0.989)$. Side effects consisted in mild transitory burning (four patients) or erythema (five patients) requiring the suspension of the treatment for one or two sessions and the dose was decreased by $50 \mathrm{~mJ} / \mathrm{cm}^{2}$ at the following procedure. All patients were followed up 6 months after the last session and no recurrences were observed.

\section{DISCUSSION}

Although many treatments have been proposed for vitiligo, outcomes were disappointing. Our results indicate that the association of $308-\mathrm{nm}$ EL with topical khellin improved the clinical outcome of patients with refractory vitiligo. Overall, 70\% of our patients showed more than $50 \%$ repigmentation and no recurrences were observed 6 months later. After promising results with 308-nm excimer laser, EL has been progressively developed and was first used with efficacy for vitiligo in 2003. In that study, 89\% $(33 / 37)$ of patients presented more than $50 \%$ repigmentation of their lesions at 3 months and $94 \%(34 / 36)$ at 6 months [3]. Since then, many studies have utilized EL as monotherapy or in combination with other drugs [7-11]. It has been proved that the 308-nm EL and the 308-nm excimer laser exhibit similar efficacy in treating vitiligo [12-14]. So, with its lower cost, we believe that EL may be preferable for clinical practice instead of the excimer laser because of a larger irradiation area with a shorter treatment period. The mechanism of action of UVB light (including lamp and laser) is the induction of $\mathrm{T}$ cell apoptosis and the stimulation of melanocyte proliferation and the migration to the epidermis from the hair follicle [5]. UVB may also stimulate keratinocytes to secrete cytokines including stem cell factor (SCF) known as activators of melanocytes and to regulate skin 

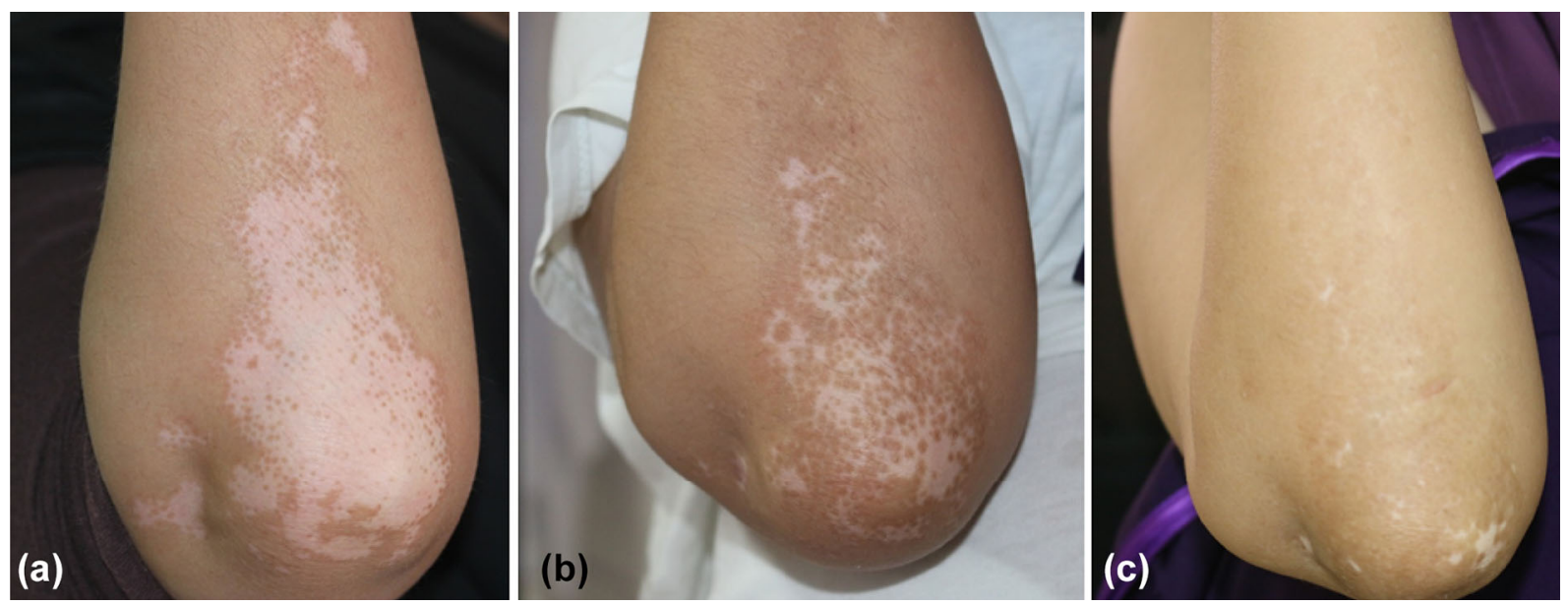

Fig. 3 a Vitiligo of the forearm before treatment. b 56 weeks after treatment. c $>90 \%$ repigmentation 1 year after treatment
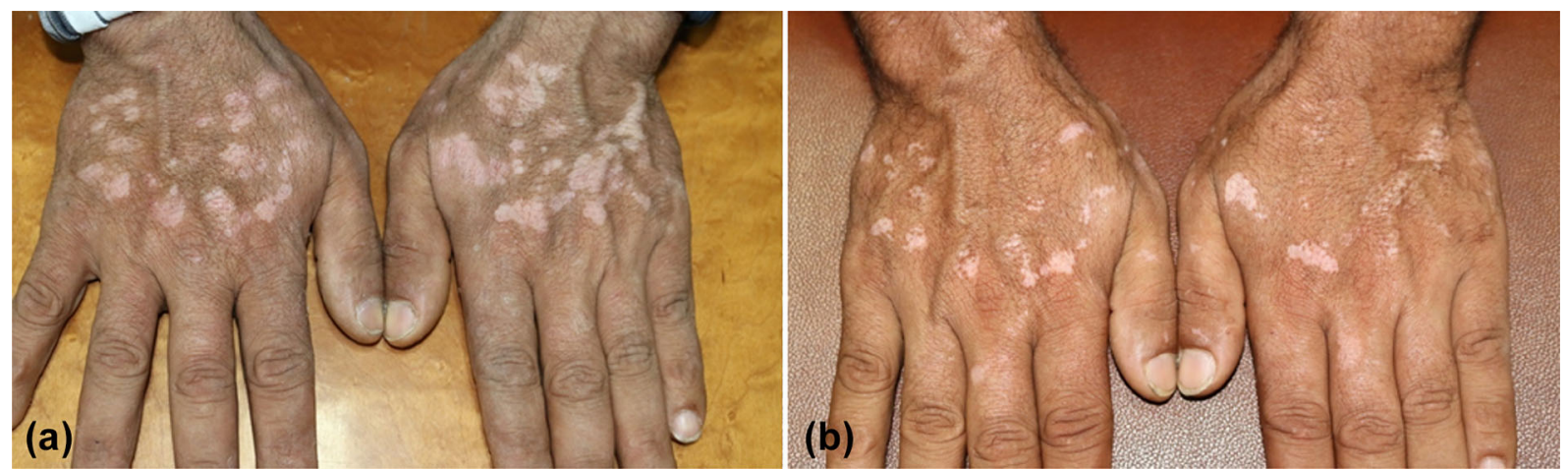

Fig. 4 a Vitiligo of the hands before treatment. $\mathbf{b}>75 \%$ repigmentation 1 year after treatment

pigmentation [15]. In fact, Park et al. recently proved that the clinical response to excimer light is highly related to c-kit+ (SCF receptor, CD117) expression in vitiliginous epidermis [16]. However, EL is not effective in all patients with vitiligo, and the combination treatment with topical drugs is widely applied to enhance the efficacy in clinical practice [7].

Khellin is a natural furanochromone isolated from a Mediterranean plant, khella, with vasodilative, spasmolytic, melanocyte proliferation stimulating, and fibroblast proliferation inhibiting activities. It is a photosensitizer whose chemical structure closely resembles that of psoralens with the same photobiological and phototherapeutics effects but without the adverse phototoxic and carcinogenic side effects observed with psoralen and ultraviolet A radiation (PUVA) treatment. Khellin acts directly on isolated melanocytes to enhance proliferation and melanogenesis $[6,17]$. It was initially introduced successfully in dermatology as treatment of vitiligo in 1982 [18] in association with natural sunlight, first as oral treatment and then as topical formulations to avoid the systemic side effects. Several preparations with different vehicles have been used to improve the properties and diffusion of the khellin: oil/water emulsions, microemulsions, cyclodextrin-containing gels, water/2-propanol/propylene glycol, liposomes. It is important to establish the right pharmaceutical approach with the correct delivery vehicle, because this will significantly improve the clinical results in vitiligo $[19,20]$. The khellin used in the current study is formulated in very low concentrations 
Table 3 Literature review of the use of khellin in the treatment of vitiligo

\begin{tabular}{|c|c|c|c|c|c|}
\hline Authors & Patients & Khellin & UV light & Follow-up (months) & Results (patients) \\
\hline \multirow[t]{5}{*}{ Nistico $[21]$} & $16\left(32^{*}\right)$ & $4 \%(1 / \mathrm{d})$ & 308-nm EL (1/w) & 3 & $8(\mathrm{~T})$ \\
\hline & & & & & ER: 4 \\
\hline & & & & & GR: 2 \\
\hline & & & & & MR: \\
\hline & & & & & PR: 2 \\
\hline \multirow[t]{3}{*}{ Saraceno [22] } & $16\left(42^{*}\right)$ & $4 \%(1 / d)$ & 308-nm EL $(1 / w)+V i t E$ & 3 & ER: 9 \\
\hline & & & & & GR: 5 \\
\hline & & & & & MR: 2 \\
\hline \multirow[t]{3}{*}{ De Leeuw [23] } & 16 & $0.005 \%(2 / \mathrm{d})$ & UVB 311-nm $(3 / \mathrm{w})+$ graft & 6 & ER: 2 \\
\hline & & & & & GR: 6 \\
\hline & & & & & MR: 8 \\
\hline De Leeuw $[24]$ & 74 & $0.005 \%(2 / \mathrm{d})$ & UVA/UVB (3-5/w) & 14 & $\begin{array}{l}\text { ER/GR: } 72 \% \text { treated } \\
\text { lesions }\end{array}$ \\
\hline \multirow[t]{4}{*}{ Valkova [25] } & $16\left(33^{*}\right)$ & $5 \%(1 / d)$ & UVA $(3-5 / w)$ & 9 & ER: 3 \\
\hline & & & & & GR: 4 \\
\hline & & & & & MR: 7 \\
\hline & & & & & PR: 2 \\
\hline \multirow[t]{4}{*}{ Orecchia $[20]$} & 36 & $1 \%$ & UVA $(3 / w)$ & 6 & ER: 11 \\
\hline & & & & & GR: 8 \\
\hline & & & & & MR: 12 \\
\hline & & & & & PR: 5 \\
\hline Hofer [26] & $17\left(28^{*}\right)$ & Oral & UVA & 3 & ER: $7 / 17$ \\
\hline \multirow[t]{3}{*}{ Ortel [27] } & 28 & Oral $[25]$ & UVA (3/w) & 21 & ER: 5 \\
\hline & & Local 2\% [3] & & & GR/MR: 8 \\
\hline & & & & & PR: $15(3 \mathrm{~L})$ \\
\hline Orecchia [28] & 41 & $2 \%(1 / \mathrm{d})$ & Sunlight & 4 & GR: $24.9 \%$ \\
\hline \multirow[t]{3}{*}{ Abdelfattah [18] } & 30 & Oral & Sunlight & 3 & ER: 5 \\
\hline & & & & & GR: 7 \\
\hline & & & & & MR/PR: 18 \\
\hline
\end{tabular}

$d$ day, $w$ week, $E L$ excimer lamp, $E R$ excellent repigmentation, $G R$ good repigmentation, $M R$ moderate repigmentation, $P R$ poor repigmentation, $L$ local application, $T$ with tacrolimus

*Total number of patients in the study 
(nanosomes). In fact, nanotechnology is characterized by the transport of active ingredients in nanometrically sized liposomes, with great power of penetration, with an increase in the efficiency, and this is in line with the correlation established now between the lower doses applied and the treatment improvement [17].

A review of the literature showed ten publications reporting the use of khellin in association with UV phototherapy in vitiligo (Table 3 ). Khellin was combined to 308-nm EL in two studies [21, 22], to UVB in one series [23], to UVA/UVB in one series [24], to UVA in four series [20, 25-27], and to sunlight in two series $[18$, 27]. The duration of the studies was between 3 and 21 months and all showed very good results except one, because the vehicle used in the concerned study did not adequately facilitate the availability of khellin [28]. Among all these trials, only two previous published reports used EL and khellin for a period of 3 months. In the group treated with khellin-EL (eight patients), Nistico found an ER in four patients, a GR in two patients, and an MR-PR in two patients, while in the group treated with khellin-EL and tacrolimus (eight patients), he found an ER in two patients, a GR in two patients, an MR in four patients, and a PR in two patients [21]. In the other study, in the group under EL-Khellin (16 patients), Saraceno observed an ER in nine patients (56.25\%), a GR in five patients $(31.25 \%)$, and a MR in two patients (12.5\%) [22]. In the present study, differently from the two previous authors, more patients were included, no other treatment was added, EL was delivered twice a week, and because all our patients were resistant to previous treatment, we have chosen to continue the treatment as long as repigmentation occurred especially in more resistant anatomical sites like hands, elbows, arm, and forearms (four patients reached 1-year treatment). In these areas (usually supposed resistant locations), at the end of the study, although the difference was not significant, the clinical outcome showed an excellent or good repigmentation like those observed in photo-exposed areas. It is interesting to note that all patients were revisited 6 months after the last procedure with no evidence of recurrences. The rapid onset of repigmentation may also play a significant role in improving patient motivation and compliance. In fact, the shortest period showing signs of pigmentation was 1 month (8 sessions), as the results reported by Leone [3] where $95 \%$ of his patients showed repigmentation within the first 8 sessions.

\section{LIMITATIONS}

Despite the limited number of patients and the nature of an open uncontrolled study design, very promising results were obtained; however, further confirmation with controlled split-face investigations, a larger sample, the best protocol design, and a longer follow-up are needed to confirm the superiority of the combination treatment over the excimer lamp as monotherapy.

\section{CONCLUSIONS}

The combination of 308-nm excimer lamp and topical khellin in the treatment of vitiligo is associated with more than $50 \%$ repigmentation in $70 \%$ of patients without significant side effects. This association would probably enhance the clinical outcome especially in more resistant anatomical sites and represent a key advancement in vitiligo therapy and a new alternative treatment. Additional controlled randomized comparative investigations are needed to confirm these results with the good therapeutic protocols.

\section{ACKNOWLEDGEMENTS}

Funding. No funding or sponsorship was received for this study or publication of this article.

Authorship. All named authors meet the International Committee of Medical Journal Editors (ICMJE) criteria for authorship for this manuscript, take responsibility for the integrity 
of the work as a whole, and have given final approval for the version to be published.

Disclosures. Samy Fenniche, Anissa Zaouak, Azima Ben Tanfous, Meriem Jrad, and Houda Hammami have nothing to disclose.

Compliance with Ethics Guidelines. All procedures followed were in accordance with the ethical standards of the responsible committee on human experimentation (institutional and national) and with the Helsinki Declaration of 1964, as revised in 2013. Informed consent was obtained from all patients for being included in the study.

Data Availability. The datasets generated and/or analyzed during the current study are not publicly available because all relevant clinical results are presented in the publication. Data are available from the corresponding author on reasonable request.

Open Access. This article is distributed under the terms of the Creative Commons Attribution-NonCommercial 4.0 International License (http://creativecommons.org/licenses/ by-nc/4.0/), which permits any noncommercial use, distribution, and reproduction in any medium, provided you give appropriate credit to the original author(s) and the source, provide a link to the Creative Commons license, and indicate if changes were made.

\section{REFERENCES}

1. Ezzedine K, Whitton M, Pinart M. Interventions for vitiligo. JAMA. 2016;316:1708-9.

2. Halder RM, Young CM. New and emerging therapies for vitiligo. Dermatol Clin. 2000;18:79-89.

3. Leone G, Iacovelli P, Paro Vidolin A, Picardo M. Monochromatic excimer light $308 \mathrm{~nm}$ in the treatment of vitiligo: a pilot study. J Eur Acad Dermatol Venereol. 2003;17:531-7.

4. Park KK, Liao W, Murase JE. A review of monochromatic excimer light in vitiligo. Br J Dermatol. 2012;167:468-78.
5. Goldstein NB, Koster MI, Hoaglin LG, et al. Narrow band ultraviolet B treatment for human vitiligo is associated with proliferation, migration, and differentiation of melanocyte precursors. J Investig Dermatol. 2015;135:2068-76.

6. Ortonne JP. Topical KUVA (khellin-UVA therapy). A future in the treatment of vitiligo? J Dermatol Treat. 1998;9:63-4.

7. Bae JM, Hong BY, Lee JH, Lee JH, Kim GM. The efficacy of 308-nm excimer laser/light (EL) and topical agent combination therapy versus EL monotherapy for vitiligo: a systematic review and meta-analysis of randomized controlled trials (RCTs). J Am Acad Dermatol. 2016;74:907-15.

8. Lu-yan T, Wen-wen F, Lei-hong X, Yi J, Zhi-zhong Z. Topical tacalcitol and 308-nm monochromatic excimer light: a synergistic combination for the treatment of vitiligo. Photodermatol Photoimmunol Photomed. 2006;22:310-4.

9. Nisticò S, Chiricozzi A, Saraceno R, Schipani C, Chimenti S. Vitiligo treatment with monochromatic excimer light and tacrolimus: results of an open randomized controlled study. Photomed Laser Surg. 2012;30:26-33.

10. Bapur Erduran F, Adışen E. Comparison of the efficacy of 308-nm excimer lamp monotherapy with topical tacrolimus or clobetasol 17-propionate combination therapies in localized vitiligo. Photodermatol Photoimmunol Photomed. 2016;32:247-53.

11. Chimento SM, Newland M, Ricotti C, Nistico S, Romanelli P. A pilot study to determine the safety and efficacy of monochromatic excimer light in the treatment of vitiligo. J Drugs Dermatol. $2008 ; 7: 258-63$.

12. Lopes C, Trevisani VF, Melnik T. Efficacy and safety of 308-nm monochromatic excimer lamp versus other phototherapy devices for vitiligo: a systematic review with meta-analysis. Am J Clin Dermatol. 2016;17:23-32.

13. Le Duff F, Fontas E, Giacchero D, et al. 308-nm excimer lamp vs. 308-nm excimer laser for treating vitiligo: a randomized study. $\mathrm{Br} \mathrm{J}$ Dermatol. 2010;163:188-92.

14. Shi Q, Li K, Fu J, et al. Comparison of the 308-nm excimer laser with the 308-nm excimer lamp in the treatment of vitiligo-a randomized bilateral comparison study. Photodermatol Photoimmunol Photomed. 2013;29:27-33.

15. Singh ZN, Tretiakova MS, Shea CR, Petronic-Rosic VM. Decreased CD117 expression in hypopigmented mycosis fungoides correlates with 
hypomelanosis: lessons learned from vitiligo. Mod Pathol. 2006;19:1255-60.

16. Park OJ, Han JS, Lee SH, et al. Expression of epidermal c-Kit+ of vitiligo lesions is related to responses to excimer laser. Ann Dermatol. 2016;28:457-63.

17. Carlie G, Ntusi NBA, Hulley PA, Kidson SH. KUVA (khellin plus ultraviolet A) stimulates proliferation and melanogenesis in normal human melanocytes and melanoma cells in vitro. $\mathrm{Br} \mathrm{J}$ Dermatol. 2003;149:707-17.

18. Abdel-Fattah A, Aboul-Enein MN, Wassel GM, ElMenshawi BS. An approach to the treatment of vitiligo by khellin. Dermatologica. 1982;165:136-40.

19. Giordano F, Rillosi M, Benelli P, et al. Preformulation studies and formulation strategies on khellin; an old/new antivitiligo agent: interaction with cyclodextrins, solubility mixed solvent systems and permeation through artificial membranes. Eur J Pharm Biopharm. 1994;40:232-6.

20. Orecchia G, Sangalli ME, Gazzaniga A, Giordano F. Topical photochemotherapy of vitiligo with a new khellin formulation: preliminary clinical results. J Dermatol. 1998;9:65-9.

21. Nistico S, Cannarozzo G, Sannino M, Del Duca E, Bottoni U. $308 \mathrm{~nm}$ UV excimer light in monotherapy or combined to topical khellin $4 \%$ and/or tacrolimus $0.1 \%$ in the treatment of vitiligo. Glob Dermatol. 2015;2:93-6.
22. Saraceno R, Nisticò SP, Capriotti E, Chimenti S. Monochromatic excimer light $308 \mathrm{~nm}$ in monotherapy and combined with topical khellin $4 \%$ in the treatment of vitiligo: a controlled study. Dermatol Ther. 2009;22:391-4.

23. de Leeuw J, Assen YJ, van der Beek N, Bjerring P, Martino Neumann HA. Treatment of vitiligo with khellin liposomes, ultraviolet light and blister roof transplantation. J Eur Acad Dermatol Venereol. 2011;25:74-81.

24. de Leeuw J, van der Beek N, Maierhofer G, Neugebauer WD. A case study to evaluate the treatment of vitiligo with khellin encapsulated in L-phenylalanin stabilized phosphatidylcholine liposomes in combination with ultraviolet light therapy. Eur J Dermatol. 2003;13:474-7.

25. Valkova S, Trashlieva M, Christova P. Treatment of vitiligo with local khellin and UVA: comparison with systemic PUVA. Clin Exp Dermatol. 2004;29:180-4.

26. Hofer A, Kerl H, Wolf P. Long-term results in the treatment of vitiligo with oral khellin plus UVA. Eur J Dermatol. 2001;11:225-9.

27. Ortel B, Tanew A, Honigsmann H. Treatment of vitiligo with khellin and ultraviolet A. J Am Acad Dermatol. 1988;18:693-701.

28. Orecchia G, Perfetti L. Photochemotherapy with topical khellin and sunlight in vitiligo. Dermatology. 1992;184:120-3. 